\title{
Clarithromycin reduces the severity of bronchial hyperresponsiveness in patients with asthma
}

\author{
E. Kostadima*, S. Tsiodras\#, E.I. Alexopoulos ${ }^{\Uparrow}$, A.G. Kaditis ${ }^{\Uparrow}$, I. Mavrou*, N. Georgatou*, \\ A. Papamichalopoulos*
}

Clarithromycin reduces the severity of bronchial hyperresponsiveness in patients with asthma. E. Kostadima, S. Tsiodras, E.I. Alexopoulos, A.G. Kaditis, I. Mavrou, N. Georgatou, A. Papamichalopoulos. (C) ERS Journals Ltd 2004.

ABSTRACT: A randomised double-blind placebo-controlled study was designed to evaluate the effects of a semisynthetic macrolide antibiotic, clarithromycin, on bronchial hyperresponsiveness to methacholine in patients with a diagnosis of asthma.

Adult asthma patients undergoing treatment with budesonide $400 \mu \mathrm{g}$ b.i.d. and salbutamol $200 \mu \mathrm{g}$ p.r.n. less than twice weekly were studied. Arm A (16 males/six females, aged $48 \pm 16 \mathrm{yrs}$ ) received clarithromycin $250 \mathrm{mg}$ b.i.d. for 8 weeks, arm B (eight males/12 females, aged $42 \pm 12 \mathrm{yrs}$ ) clarithromycin $250 \mathrm{mg}$ t.i.d. and arm C (six males/15 females, aged $41 \pm 16$ yrs) placebo dextrose tablets. Bronchial hyperresponsiveness was quantified by measurement of the provocative dose of methacholine causing a $20 \%$ fall in forced expiratory volume in one second (PD20).

Median (interquartile range) $\mathrm{PD20}$ in the three groups before and after treatment with clarithromycin were: $\operatorname{arm} \mathrm{A}: 0.3(0.1-1)$ and $1.3(0.6-2) \mathrm{mg}$; $\mathrm{arm} \mathrm{B}: 0.4(0.1-0.9)$ and $2(2-2) \mathrm{mg}$; and arm C: $0.4(0.1-0.9)$ and $0.3(0.1-0.6) \mathrm{mg}$, respectively. Serum free cortisol levels were determined and remained unchanged from baseline in the clarithromycin-treated patients.

It is concluded that clarithromycin reduces the degree of bronchial hyperresponsiveness in patients with asthma.

Eur Respir J 2004; 23: 714-717. *10th Respiratory Dept, Athens Chest Hospital, and ${ }^{\#}$ University of Athens School of Medicine, University of Athens, Athens, and "Paediatric Pulmonology Unit, Dept of Paediatrics, University of Thessaly School of Medicine and Larissa University Hospital, Larissa, Greece.

Correspondence: E. Kostadima

Chrisostomou Smirnis 2

Larissa

Greece

Fax: 302410670838

E-mail: ealexop@yahoo.com

Keywords: Bronchial asthma bronchial hyperresponsiveness clarithromycin

macrolides

Received: October 222003

Accepted after revision: January 232004
Asthma is characterised by bronchial hyperresponsiveness (BHR) to nonspecific stimuli such as histamine, methacholine, cold air and exercise. BHR is related to airway inflammation and the degree of BHR indirectly reflects the severity of the disease [1]. Systemic corticosteroids administered on a long-term basis reduce BHR, but their use has been associated with significant side-effects. Modern asthma research is orientated towards the use of inhaled corticosteroids, which also decrease BHR, or alternative drug therapies possessing less toxic immunosuppressive, immunomodulating and antiinflammatory qualities.

Macrolides such as troleandomycin and erythromycin have been shown to be effective in the treatment of asthma [2, 3]. Their action in the steroid-dependent asthmatic patient is mediated at least in part by decreased corticosteroid metabolism. For example, troleandomycin and clarithromycin decrease methylprednisolone clearance and increase plasma methylprednisolone levels [4, 5]. However, clarithromycin does not have a significant effect on prednisolone elimination [5]. Erythromycin and especially the newer macrolides (e.g. roxithromycin, clarithromycin and azithromycin) exert specific anti-inflammatory effects, including inhibition of generation of reactive oxygen species by polymorphonuclear leucocytes $[6,7]$. In addition, macrolide antibiotics may improve lung function due to their activity against Mycoplasma pneumoniae and Chlamydia pneumoniae, which are involved in asthma exacerbations [8-10].

As a result of the actions described above, macrolides probably reduce the severity of BHR in adults and children with asthma. Most published data on reduction of BHR refer to erythromycin, roxithromycin or azithromycin [11-13]. There are very few data on the suppression of BHR in patients with asthma following treatment with clarithromycin [14] and carefully designed controlled studies are lacking.

In the present investigation, the effects of clarithromycin on BHR in patients with bronchial asthma were evaluated. The hypothesis was that administration of clarithromycin for 8 weeks decreases the degree of BHR to methacholine.

\section{Materials and methods}

\section{Study design}

The present study was designed as a randomised doubleblind placebo-controlled trial. Subjects who fulfilled the following inclusion criteria were studied: 1) age 18-70 yrs; 2) established diagnosis of bronchial asthma for $\geqslant 1$ yr [1]; 3) treatment with budesonide $400 \mu \mathrm{g}$ b.i.d. and salbutamol 200 $\mu \mathrm{g}$ p.r.n. less than twice weekly for $\geqslant 1$ month prior to recruitment; and 4) a provocative dose of methacholine causing a $20 \%$ fall in forced expiratory volume in one second (FEV1) (PD20) of $<2 \mathrm{mg}$.

During the study, patients continued their treatment with budesonide and salbutamol. No other medication was allowed Exclusion criteria were as follows: 1) a history of allergic rhinitis or occupational asthma; 2) a history of smoking (past or current); 3) treatment with systemic corticosteroids or a history of upper respiratory tract infection over the 4 weeks prior to participation in the trial; 4) an FEV1 of $<50 \%$ of the 
predicted value or of $<1 \mathrm{~L}$ at baseline; 5) upper respiratory tract infection or asthma exacerbation during the study period; 6) a history of systemic diseases (i.e. heart attack or stroke in the previous 3 months, uncontrolled hypertension, known aortic aneurysm, epilepsy requiring drug treatment and peptic ulcer disease); 7) treatment with $\beta$-blockers; and 8) pregnancy or nursing mothers $[15,16]$.

After giving informed consent, each patient was randomised to one of the study groups $(\mathrm{A}-\mathrm{C})$ by a research nurse who played no further role in the study. Recruitment was discontinued when 75 patients were randomised ( 25 per arm). Patients and investigators were blinded with regard to the type of treatment received. The study was approved by the scientific review board of Athens Chest Hospital (Athens, Greece).

\section{Methods}

All patients were submitted to a methacholine inhalation challenge test to evaluate BHR at baseline and $24 \mathrm{~h}$ after completion of the trial. Patients in arm A of the study received clarithromycin $250 \mathrm{mg}$ b.i.d. for 8 weeks. In Arm B, clarithromycin $250 \mathrm{mg}$ t.i.d was prescribed for 8 weeks. Arm $\mathrm{C}$, the control group, received placebo dextrose tablets indistinguishable from the clarithromycin tablets for 8 weeks. Bronchodilator therapy was discontinued $\geqslant 12 \mathrm{~h}$ before the provocation test.

The methacholine inhalation challenge method has been described in detail elsewhere [15]. In summary, ampoules of methacholine hydrochloride (Lofarma, Milan, Italy) were stored at $4{ }^{\circ} \mathrm{C}$ and then kept at room temperature for $30 \mathrm{~min}$ before use. Aerosols of methacholine were generated using a jet nebuliser. A Dosimeter MB3 (Mefar, Bovezzo, Italy), with a valve system enabling the administration of aerosol only during inspiration, was used. A flow sensor in the expiratory port triggers a solenoid valve which exposes the nebuliser to compressed air at $138 \mathrm{kPa}$ for $\sim 0.6 \mathrm{~s}$ to give a calibrated output of $9.0 \mu \mathrm{L} \cdot$ puff $^{-1}$.

A nose clip was used and the bolus of aerosol inhaled through the mouth over $5 \mathrm{~s}$ during an inspiratory capacity breath without breath-holding at total lung capacity. An aerosol of normal saline solution (diluent) was inhaled first, followed by increasing doses of methacholine $(0.0156,0.0625$, $0.2590,1.000$ and $2.000 \mathrm{mg}$ ). The doses were administered at 5-min intervals. FEV1 was measured 2 min after each inhalation. The test was terminated when FEV1 had fallen by $\geqslant 20 \%$ compared to inhalation of control saline solution, or until a cumulative dose of $2 \mathrm{mg}$ was reached. PD20 was calculated exactly [15]. For the purposes of statistical analysis, subjects who received the maximum dose $(2 \mathrm{mg})$ with a fall in FEV1 of $<20 \%$ were considered to have a PD20 of $2 \mathrm{mg}$.

During the study, laboratory assessment of total blood count, renal function and liver function was performed biweekly. Baseline and end-of-study serum free cortisol levels were measured in a subgroup of participants.

\section{Statistics}

Descriptive statistics are presented as either median (interquartile range) or mean $\pm \mathrm{SD}$. In each of the treatment groups (A, B or C), PD20 and spirometric indices before and after treatment with the study medication were compared using a Wilcoxon signed-rank test (for non-normally distributed variables) or a two-tailed paired t-test (for normally distributed variables). Changes in PD20 after treatment with the study medication in the $500-\mathrm{mg} \cdot \mathrm{day}^{-1}$ and $750-\mathrm{mg} \cdot \mathrm{day}^{-1}$ clarithromycin groups were compared using the two-independentsample nonparametric test (Mann-Whitney test).

\section{Results}

\section{Subject characteristics}

Overall, 75 patients were recruited, 25 in each arm. However, three patients from group A were excluded from further study: one presented with an asthmatic exacerbation due to an infection and two refused to complete the 8-week treatment with the study medication. In group B, 20 patients met the eligibility criteria and five were excluded from the analysis: three presented with acute asthma exacerbation and one with a gastrointestinal disorder during the trial, whereas the final one refused to complete treatment with the study medication. In group C, 21 patients remained in the analysis as three patients presented with a severe asthma exacerbation and one did not complete the treatment and for this reason was excluded from further study.

Overall, results were analysed for 63 patients, 22 in group A, 20 in group B and 21 in group C. In groups A, B and C, Six of $22(27 \%), 12$ of $20(60 \%)$ and 15 of $21(71 \%)$ patients were female, respectively. The mean $\pm \mathrm{SD}$ age of the patients was $48 \pm 16,42 \pm 12$ and $41 \pm 16$ yrs in groups $\mathrm{A}, \mathrm{B}$ and $\mathrm{C}$, respectively ( $\mathrm{p}=\mathrm{NS}$ in between-group comparisons). Mean baseline spirometric indices (FEV1 as a percentage of the predicted value, FVC and FEV1/FVC ratio) and median PD20 were similar between subjects of the three groups $(\mathrm{p}>0.05)$ (table 1).

\section{Spirometric indices and provocative dose of methacholine} causing a 20\% fall in forced expiratory volume in one second

Spirometric indices and PD20 before and after study medication are presented in table 1. Mean FEV1 and FVC

Table 1.- Provocative dose of methacholine causing a $20 \%$ fall in forced expiratory volume in one second (FEV 1 ) (PD20) and spirometric indices before and after study medication in the three groups ${ }^{\#}$

\begin{tabular}{|c|c|c|c|c|c|c|}
\hline & \multicolumn{2}{|c|}{ Group A } & \multicolumn{2}{|c|}{ Group B } & \multicolumn{2}{|c|}{ Group C } \\
\hline & Before & After & Before & After & Before & After \\
\hline Subjects n & \multicolumn{2}{|c|}{22} & \multicolumn{2}{|c|}{20} & \multicolumn{2}{|c|}{21} \\
\hline PD20 mg & $0.3(0.1-1)$ & $1.3(0.6-2)^{* * *}$ & $0.4(0.1-0.9)$ & $2(2-2) * * *$ & $0.4(0.1-0.9)$ & $0.3(0.1-0.6)$ \\
\hline FEV1 \% pred & $85 \pm 14$ & $85 \pm 12$ & $85 \pm 13$ & $88 \pm 12 * * *$ & $86 \pm 14$ & $88 \pm 15$ \\
\hline FVC \% pred & $96 \pm 10$ & $96 \pm 11$ & $92 \pm 10$ & $92 \pm 9$ & $87 \pm 15$ & $89 \pm 15$ \\
\hline FEV1/FVC & $72 \pm 14$ & $72 \pm 11$ & $75 \pm 5$ & $78 \pm 5 * * *$ & $80 \pm 5$ & $79 \pm 7$ \\
\hline
\end{tabular}

Data are presented as median (interquartile range) or mean \pm SD. FVC: forced vital capacity; $\%$ pred: per cent predicted. ${ }^{\#}$ : arm A patients received clarithromycin $250 \mathrm{mg}$ b.i.d. for 8 weeks, arm B clarithromycin $250 \mathrm{mg}$ t.i.d and arm C, the control group, placebo dextrose tablets indistinguishable from the clarithromycin tablets. $* * *: p \leqslant 0.001$ versus before study medication. 


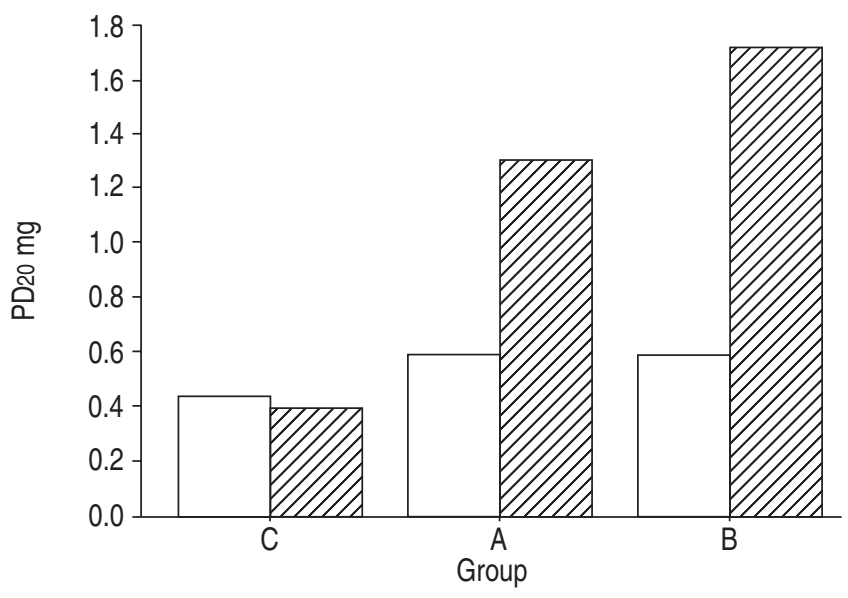

Fig. 1. - Mean provocative dose of methacholine causing a $20 \%$ fall in forced expiratory volume in one second (PD20) at baseline ( $\square$ ) and after study medication $(\mathbb{Z})$ in the placebo $(\mathrm{C})$ and $500-\mathrm{mg} \cdot \mathrm{day}^{-1}$ (A) and $750-\mathrm{mg}^{-\mathrm{day}^{-1}}$ (B) clarithromycin groups. PD20 after treatment are higher compared to baseline in the $500-\mathrm{mg} \cdot \mathrm{day}^{-1}$ and $750-\mathrm{mg} \cdot \mathrm{day}^{-1}$ clarithromycin groups $(\mathrm{p}<0.001)$ but not in the placebo group.

as a percentage of the predicted value before and after treatment remained unchanged in patients of groups $\mathrm{A}$ and $\mathrm{C}$ $(\mathrm{p}>0.05)$. Compared to baseline, there was a significant increase in the median PD20 in the two clarithromycin-treated groups (A and B) but not in the placebo-treated group (C) (table 1; fig. 1). More specifically, median (interquartile range) $\mathrm{PD} 20$ in the three groups before and after treatment with study medication were: arm A: $0.3(0.1-1)$ and $1.3(0.6-2)$ $\mathrm{mg}(\mathrm{p}<0.001)$; arm B: $0.4(0.1-0.9)$ and $2(2-2) \mathrm{mg}(\mathrm{p}<0.001)$; and arm C: $0.4(0.1-0.9)$ and $0.3(0.1-0.6) \mathrm{mg}(\mathrm{p}>0.05)$.

Individual PD20 data at baseline and after treatment are presented in figure 2. PD20 increased in 19 of the 22 subjects in group A (clarithromycin $500 \mathrm{mg} \cdot \mathrm{day}^{-1}$ ), 19 of the 20 subjects in group B (clarithromycin $750 \mathrm{mg} \cdot$ day $^{-1}$ ) and nine of the 21 subjects in group $\mathrm{C}$ (placebo). No subgroups of patients could be clearly identified within each treatment group. The clarithromycin effects on BHR were independent of age and sex (data not shown).

Comparison of the changes in PD20 (before and after study medication) between groups A and B showed a trend favouring the higher-dose regimen, which did not reach significance
(Mann-Whitney test; $\mathrm{p}=0.07$ ) (fig. 1). FEV1 was higher by $3 \%$ pred in the $750-\mathrm{mg} \cdot \mathrm{day}^{-1}$ clarithromycin group after treatment compared to baseline $(\mathrm{p}=0.001)$.

Serum free cortisol levels were measured in 40 patients. Of these, 25 belonged to groups A and B. Measurement of endogenous cortisol levels in the patients who received clarithromycin revealed no significant changes from baseline values $(\mathrm{p}>0.05)$.

\section{Discussion}

In the present investigation, BHR in patients with asthma improved significantly after completion of an 8-week clarithromycin regimen compared to placebo. The change in PD20 between baseline and following treatment in the $500-\mathrm{mg} \cdot \mathrm{day}^{-1}$ clarithromycin group compared to the $750-\mathrm{mg} \cdot \mathrm{day}^{-\mathrm{P}}$ clarithromycin group approached but did not reach significance.

There were no significant changes in spirometric indices in any of the three groups except for FEV1 in the 750-mg day $^{-1}$ clarithromycin-treated subjects. However, a $3 \%$ change in this parameter is not clinically significant [17]. No change in mean FEV1 as a percentage of the predicted value was noted after a 10 -week trial of erythromycin administered to 23 asymptomatic subjects with asthma who were not receiving oral or inhaled corticosteroids and who had baseline FEV1 similar to those of the patients in the present study [11]. Likewise, no change in FEV1 or FVC was reported in a double-blind placebo-controlled study of clarithromycin administered to 17 adults with mild-to-moderate asthma [14] or in a trial of roxithromycin given to 12 asthmatic children [12]. Both medications were studied for 8 weeks. Therefore, it does not seem that clarithromycin exerts its effect on BHR in mild asthmatics via bronchodilation.

Several pathophysiological mechanisms could explain the clarithromycin effect on the present asthmatic subjects. The beneficial action of macrolides was initially attributed to reduced corticosteroid elimination, with troleandomycin being the characteristic example [3, 4, 18]. In the present study, no change in serum free cortisol levels was found after treatment and, therefore, it is unlikely that clarithromycin affected the metabolism of endogenous corticosteroids.

The anti-inflammatory action of macrolides may be an alternative explanation for their beneficial action on BHR. Macrolides could exert their anti-inflammatory effects via several antioxidant properties of their molecule, resulting in
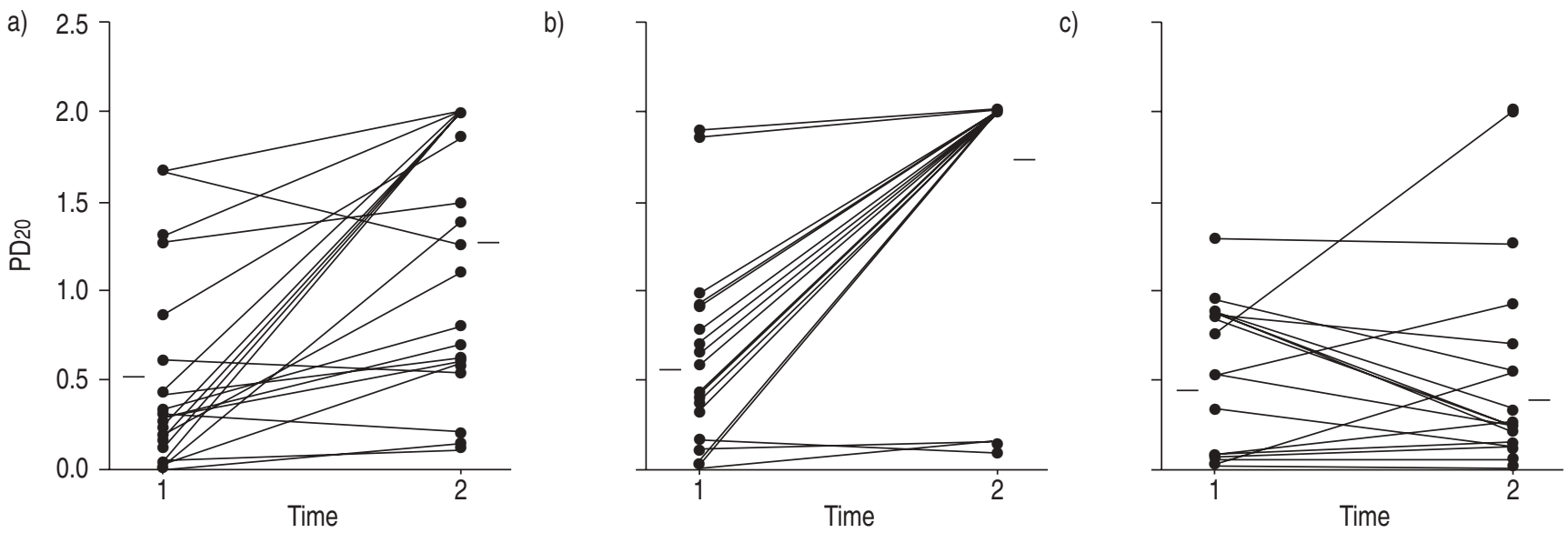

Fig. 2.-Provocative dose of methacholine causing a $20 \%$ fall in forced expiratory volume in one second (PD20) at baseline (1) and after study medication (2) for individual subjects receiving a) clarithromycin $500 \mathrm{mg}^{\circ} \mathrm{day}^{-1}$, b) clarithromycin $750 \mathrm{mg} \cdot \mathrm{day}{ }^{-1}$ and c) placebo. Horizontal bars represent means. 
inhibition of superoxide generation by polymorphonuclear leucocytes [6]. FELDMAN et al. [19] proposed that macrolides may have beneficial effects on airway inflammation in asthma by protecting ciliated epithelium against oxidative damage inflicted by phospholipid-sensitised phagocytes.

Interestingly, newer macrolides have inhibitory effects on cytokine secretion from leukocytes, especially interleukins-2, -3 and -4 and tumour necrosis factor- $\alpha$ [20], whereas erythromycin and clarithromycin exert a concentration-dependent suppressive effect on interleukin-8 release by human eosinophils from atopic donors [21]. Suppression of the interleukin5-induced prolongation of eosinophil survival could further contribute to their effect [22]. Clarithromycin use resulted in improved symptoms as well as decreased levels of sputum eosinophils and eosinophil cationic protein in a study of asthmatic patients [14]

An effect on the neural component of airway smooth muscle contraction could explain some of the beneficial results of macrolides in asthmatic subjects. It has been suggested that their use may inhibit cholinergic neuroeffector transmission in human airway smooth muscle [23]. Furthermore, erythromycin and clarithromycin interfere with the formation of endothelin-1, a bronchoconstricting peptide which probably plays a major role in the pathogenesis of asthma [24].

Last but not least, clarithromycin could improve BHR through its antimicrobial activity since, in some individuals, infection with $C$. pneumoniae and/or other microorganisms may be associated with asthma exacerbations [8, 25, 26]. In a randomised double-blind placebo-controlled trial in asthmatic adults, treatment with clarithromycin for 6 weeks improved lung function in those who had M. pneumoniae or C. pneumoniae identified in their airways by polymerase chain reaction (PCR) [8]. Lung function did not improve in PCRnegative subjects.

The strengths of the current study include its prospective placebo-controlled double-blind nature. Additionally, by virtue of its design, it adjusts for several confounding factors, including concomitant conditions, the effect of asthma exacerbations and other medication use. Issues for further investigation are the cost-effectiveness of such an approach in the clinical setting and the duration of the effect on bronchial hyperresponsiveness, as well as the issue of the development of bacterial resistance associated with long-term antibiotic use. Nevertheless, the present investigation confirms the beneficial effect of clarithromycin use on bronchial hyperresponsiveness in patients with asthma. Clarithromycin could potentially be useful as an adjunctive therapy in the treatment of asthma.

\section{References}

1. Global Initiative for Asthma. Global Strategy for Asthma Management and Prevention. NIH publication No. 02-3659. Bethesda, MD, National Heart, Lung and Blood Institute, 2002.

2. Cott GR, Cherniack RM. Steroids and "steroid-sparing" agents in asthma. N Engl J Med 1988; 318: 634-636.

3. Spector SL, Katz FH, Farr RS. Troleandomycin: effectiveness in steroid-dependent asthma and bronchitis. J Allergy Clin Immunol 1974; 54: 367-379.

4. Szefler SJ, Rose JQ, Ellis EF, Spector SL, Green AW, Jusko WJ. The effect of troleandomycin on methylprednisolone elimination. J Allergy Clin Immunol 1980; 66: 447-451.

5. Fost DA, Leung DY, Martin RJ, Brown EE, Szefler SJ, Spahn JD. Inhibition of methylprednisolone elimination in the presence of clarithromycin therapy. $J$ Allergy Clin Immunol 1999; 103: 1031-1035.

6. Anderson R. Erythromycin and roxithromycin potentiate human neutrophil locomotion in vitro by inhibition of leukoattractant-activated superoxide generation and autooxidation. J Infect Dis 1989; 159: 966-973.

7. Anderson R, Theron AJ, Feldman C. Membrane-stabilizing, anti-inflammatory interactions of macrolides with human neutrophils. Inflammation 1996; 20: 693-705.

8. Kraft M, Cassell GH, Pak J, Martin RJ. Mycoplasma pneumoniae and Chlamydia pneumoniae in asthma: effect of clarithromycin. Chest 2002; 121: 1782-1788.

9. Gil JC, Cedillo RL, Mayagoitia BG, Paz MD. Isolation of Mycoplasma pneumoniae from asthmatic patients. Ann Allergy 1993; 70: 23-25.

10. Allegra L, Blasi F, Centanni S, et al. Acute exacerbations of asthma in adults: role of Chlamydia pneumoniae infection. Eur Respir J 1994; 7: 2165-2168.

11. Miyatake H, Taki F, Taniguchi H, Suzuki R, Takagi K, Satake T. Erythromycin reduces the severity of bronchial hyperresponsiveness in asthma. Chest 1991; 99: 670-673.

12. Shimizu T, Kato M, Mochizuki H, Tokuyama K, Morikawa A, Kuroume T. Roxithromycin reduces the degree of bronchial hyperresponsiveness in children with asthma. Chest 1994; 106: 458-461.

13. Ekici A, Ekici M, Erdemoglu AK. Effect of azithromycin on the severity of bronchial hyperresponsiveness in patients with mild asthma. J Asthma 2002; 39: 181-185.

14. Amayasu H, Yoshida S, Ebana S, et al. Clarithromycin suppresses bronchial hyperresponsiveness associated with eosinophilic inflammation in patients with asthma. Ann Allergy Asthma Immunol 2000; 84: 594-598.

15. Sterk PJ, Fabbri LM, Quanjer PH, et al. Airway responsiveness. Standardized challenge testing with pharmacological, physical and sensitizing stimuli in adults. Eur Respir J 1993; 6: Suppl. 16, 53-83.

16. Crapo RO, Casaburi R, Coates AL, et al. Guidelines for methacholine and exercise challenge testing - 1999. Am J Respir Crit Care Med 2000; 161: 309-329.

17. American Thoracic Society. Lung function testing: selection of reference values and interpretative strategies. American Thoracic Society. Am Rev Respir Dis 1991; 144: 1202-1218.

18. Kamada AK, Hill MR, Ikle DN, Brenner AM, Szefler SJ Efficacy and safety of low-dose troleandomycin therapy in children with severe, steroid-requiring asthma. J Allergy Clin Immunol 1993; 91: 873-882.

19. Feldman C, Anderson R, Theron AJ, Ramafi G, Cole PJ, Wilson R. Roxithromycin, clarithromycin, and azithromycin attenuate the injurious effects of bioactive phospholipids on human respiratory epithelium in vitro. Inflammation 1997; 21 : 655-665.

20. Konno S, Asano K, Kurokawa M, Ikeda K, Okamoto K, Adachi M. Antiasthmatic activity of a macrolide antibiotic, roxithromycin: analysis of possible mechanisms in vitro and in vivo. Int Arch Allergy Immunol 1994; 105: 308-316.

21. Kohyama T, Takizawa H, Kawasaki S, Akiyama N, Sato M, Ito K. Fourteen-member macrolides inhibit interleukin-8 release by human eosinophils from atopic donors. Antimicrob Agents Chemother 1999; 43: 907-911.

22. Adachi T, Motojima S, Hirata A, et al. Eosinophil apoptosis caused by theophylline, glucocorticoids, and macrolides after stimulation with IL-5. J Allergy Clin Immunol 1996; 98: S207-S215.

23. Tamaoki J, Tagaya E, Sakai A, Konno K. Effects of macrolide antibiotics on neurally mediated contraction of human isolated bronchus. J Allergy Clin Immunol 1995; 95: 853-859.

24. Takizawa H, Desaki M, Ohtoshi $\mathrm{T}$, et al. Erythromycin and clarithromycin attenuate cytokine-induced endothelin-1 expression in human bronchial epithelial cells. Eur Respir $J$ 1998; 12: 57-63.

25. Emre U, Roblin PM, Gelling M, et al. The association of Chlamydia pneumoniae infection and reactive airway disease in children. Arch Pediatr Adolesc Med 1994; 148: 727-732.

26. Gendrel D. Intracellular pathogens and asthma: Mycoplasma pneumoniae and Chlamydia pneumoniae in paediatric patients. Eur Respir Rev 1996; 6: 38, 231-234. 